Л.С. Намазова-Баранова1, 2, 3, Т.Е. Привалова1, 2, В.А. Булгакова 1, 2 , Ю.И. Ермакова 2,4 , М.В. Федосеенко 1,2 , Д.С. Русинова 2,5 , Т.А. Калюжная ${ }^{1,2}$, Е.А. Вишнева1, 2 , Ф.Ч. Шахтахтинская 1 , 2 , М.В. Фоминых 1,2

1 НИИ педиатрии и охраны здоровья детей ЦКБ РАН Министерства науки и высшего образования РФ, Москва, Российская Федерация

2 Российский национальный исследовательский медицинский университет им. Н.И. Пирогова, Москва, Российская Федерация

3 Белгородский государственный национальный исследовательский университет, Белгород, Российская Федерация

4 ФГБУ ГНЦ ФМБЦ им. А.И. Бурназяна ФМБА России Москва, Российская Федерация

5 Детская городская поликлиника № 133 департамента здравоохранения города Москвы, Москва, Российская Федерация

\title{
Место дисциплины
} “вакцинопрофилактика здоровых детей и детей с хроническими заболеваниями" в учебном плане подготовки специалиста по направлению "педиатрия"

Автор, ответственный за переписку:

Привалова Татьяна Евгеньевна, кандидат медицинских наук, заведующая учебной частью, доцент кафедры факультетской педиатрии педиатрического факультета ФГАОУ ВО “Российский национальный исследовательский медицинский университет им. Н.И. Пирогова", ведущий научный сотрудник НИИ педиатрии и охраны здоровья детей ЦКБ РАН Министерства науки и высшего образования Российской Федерации Адрес: 117997, г. Москва, ул. Островитянова, д. 1, e-mail: kafedra.fp@yandex.ru

В статье представлен опыт преподавания дисциплины «Вакцинопрофилактика здоровых детей и детей с хроническими заболеваниями" и обоснована ее актуальность в обучении студентов педиатрических факультетов высших учебных заведений России. Показано, что большинство студентов положительно относятся к вакцинации, однако недостаточно информированы в вопросах организации самого процесса и нуждаются в получении этих знаний. Ключевые слова: вакцинопрофилактика, иммунопрофилактика, вакцинация, иммунизация, преподавание на педиатрическом факультете, медицинское образование, рабочая программа, федеральный образовательный стандарт, социологический опрос, анкетирование

Для цитирования: Намазова-Баранова Л.С., Привалова Т.Е., Булгакова В.А., Ермакова Ю.И., Федосеенко М.В., Русинова Д.С., Калюжная Т.А., Вишнева Е.А., Шахтахтинская Ф.Ч., Фоминых М.В. Место дисциплины «вакцинопрофилактика здоровых детей и детей с хроническими заболеваниями" в учебном плане подготовки специалиста по направлению “педиатрия». Педиатрическая фармакология. 2021;18(1):48-51. doi: 10.15690/pf.v18i1.2232

Вакцинопрофилактика (вакцинация, иммунопрофилактика, иммунизация населения) - самые распространенные и наиболее часто используемые термины в течение последних десяти лет и особенно последнего года. Вопросы вакцинации обсуждаются в СМИ, медицинских сообществах, среди неформальных лидеров и блогеров, на предприятиях, среди домохозяек и пр.

Цель вакцинации - создание коллективного иммунитета, т.е. невосприимчивости населения к определенным инфекциям (специфическим и неспецифическим), которые вызывают ряд заболеваний (часто протекающих в тяжелой форме, с развитием опасных осложнений вплоть до летального исхода).

Всемирная организация здравоохранения в 2019 г. впервые в истории включила отказ от прививок в список десяти глобальных угроз для человечества, так как отказ населения от вакцинации может спровоцировать вспышки многих предотвратимых инфекционных и ассоциированных с ними заболеваний, а также повысить смертность от них [1]. Недоверие к вакцинации - сложное и противоречивое явление, связанное не только с медицинскими факторами, но и с социальными, психологическими, религиозными и другими составляющими современной жизни, поэтому требует всестороннего изучения [2]. При этом особое значение имеют разработка и внедрение новых форм преодоления антипрививочных настроений.

Согласно приказу Минздрава России № $125 \mathrm{H}$ от 21 марта 2014 г., специалисты медицинских организаций, проводящие вакцинацию, должны пройти обучение по вопросам применения иммунобиологических лекарственных препаратов для иммунопрофилактики инфек- 
ционных болезней и получить удостоверение о повышении квалификации [3].

Но, несмотря на то, что указанный документ был опубликован более шести лет назад, детальных методических рекомендаций по осуществлению преподавания вопросов вакцинопрофилактики до настоящего времени нет.

Анализ "учебных планов подготовки специалистов" по направлению подготовки (специальность) 31.05.02 "педиатрия" в разных медицинских вузах России за последние пять лет (после перехода на обучение по новому образовательному стандарту ФГОС ВО) позволяет утверждать, что система преподавания вопросов вакцинопрофилактики неэффективна.

На сегодняшний день в большинстве медицинских вузов нашей страны в процессе обучения студентов педиатрического факультета на преподавание вопросов вакцинопрофилактики выделяется в среднем 2-4 академических часа в рамках таких дисциплин, как микробиология, пропедевтика детских болезней (в единичных вузах), инфекционные болезни, инфекционные болезни детского возраста, поликлиническая педиатрия. Для студентов лечебного факультета - еще меньше. Выживаемость знаний, полученных в таком формате, минимальна. На это указывают и результаты опроса самих студентов. Вот некоторые ответы студентов, полученные при анкетировании в опросе открытого типа на вопрос "На каких кафедрах вы изучали вакцинопрофилактику инфекционных болезней?" (большинство респондентов написало 2-3 варианта ответа):

- «Азы на микробиологии, на факультетской педиатрии акцентируется внимание на особенности вакцинопрофилактики при различных заболеваниях";

- "Частично на кафедрах микробиологии и пропедевтики детских болезней";

- «Радует, что сейчас на каждом занятии по факультетской педиатрии мы уделяем время вакцинопрофилактике".
Не предусмотрено преподавание вакцинопрофилактики как отдельной дисциплины и для ординаторов, обучающихся по специальностям "педиатрия" и "терапия", не говоря уже о других узких специальностях.

Обучение в области вакцинопрофилактики в основном представлено на последипломном этапе циклами тематического усовершенствования, программами повышения квалификации для медицинских и фармацевтических работников, курсами по вакцинопрофилактике для врачей и медицинских сестер (например, «Актуальные вопросы вакцинации", "Вакцинопрофилактика" и т.п.) трудоемкостью 36-72 ч. Подобные курсы проводятся институтом переподготовки и повышения квалификации кадров, факультетами дополнительного профессионального образования, коммерческими учебными заведениями без государственной аккредитации, часто дистанционно. В 2019 г. в Кубанском государственном медицинском университете был введен курс по вакцинопрофилактике для студентов 6-го курса педиатрического факультета. Однако не была создана единая рабочая программа, охватывающая все важные аспекты данной отрасли современной медицины, а также нет четких методических рекомендаций по обеспечению педагогического процесса. В результате обучающиеся и слушатели не получают необходимые знания в полном объеме, в то время как антипрививочное движение активно развивается.

Кафедра факультетской педиатрии педиатрического факультета РНИМУ им. Н.И. Пирогова с 2016-2017 учебного года в условиях реализации нового образовательного стандарта ФГОС ВО № 853, утвержденного Министерством образования и науки РФ 17 августа 2015 г., при поддержке руководства университета предложила ввести и начала преподавать новую учебную дисциплину «Вакцинопрофилактика здоровых детей и детей с хроническими заболеваниями" (вариативная часть, обязательная дисциплина - C1.В.О.) за счет

Leyla S. Namazova-Baranova1, 2, 3, Tatiana E. Privalova1, 2, Vilya A. Bulgakova1, 2,

Yuliya I. Ermakova2, 4, Marina V. Fedoseenko1, 2, Dina S. Rusinova ${ }^{2,5}$, Tatiana A. Kalyuzhnaya ${ }^{1,2}$,

Elena A. Vishneva1, 2, Firuza Ch. Shakhtakhtinskaya ${ }^{1,2}$, Maria V. Fominykh1, 2

1 Research Institute of Pediatrics and Children's Health in "Central Clinical Hospital of the Russian Academy of Sciences", Moscow, Russian Federation

2 Pirogov Russian National Research Medical University, Moscow, Russian Federation

3 Belgorod State National Research University, Belgorod, Russian Federation

4 Russian State Research Center - Burnasyan Federal Medical Biophysical Center of Federal Medical Biological Agency, Moscow, Russian Federation

5 Children's City Outpatients Clinic № 133 of the Moscow Health Care Department, Moscow, Russian Federation

\section{The Role of "Preventive Vaccination in Healthy Children and Children with Chronic Diseases" Discipline in the Specialist Training Curriculum in the Field of "Pediatrics"}

This article presents the experience of teaching the discipline "Preventive Vaccination in Healthy Children and Children with Chronic Diseases". Its significance in preparation of students of pediatric departments of higher educational institutions of Russia is validated. It is shown that the majority of students have positive attitude to vaccination, however, they are not sufficiently informed about the organization of the process itself and they need to obtain such knowledge.

Keywords: preventive vaccination, preventive immunization, vaccination, immunization, teaching on pediatric department, medical education, work program, federal educational standard, sociological survey, questionnaire.

For citation: Namazova-Baranova Leyla S., Privalova Tatiana E., Bulgakova Vilya A., Ermakova Yuliya I., Fedoseenko Marina V., Rusinova Dina S., Kalyuzhnaya Tatiana A., Vishneva Elena A., Shakhtakhtinskaya Firuza Ch., Fominykh Maria V. The Role of "Preventive Vaccination in Healthy Children and Children with Chronic Diseases" Discipline in the Specialist Training Curriculum in the Field of “Pediatrics". Pediatricheskaya farmakologiya - Pediatric pharmacology. 2021;18(1):48-51. doi: 10.15690/pf.v18i1.2232 
"вузовского компонента". Общая трудоемкость дисциплины составляет 72 ч, преподавание ведется в 12-м семестре.

Целью преподавания дисциплины «Вакцинопрофилактика здоровых детей и детей с хроническими заболеваниями" является изучение современных подходов к проведению профилактических прививок здоровым детям и детям с хроническими заболеваниями, позволяющих осуществлять активную иммунизацию, что необходимо для выполнения профессиональной деятельности врача-педиатра.

Цели и задачи дисциплины "Вакцинопрофилактика здоровых детей и детей с хроническими заболеваниями" сформулированы в соответствии с компетенциями, направленными на формирование общекультурных, общепрофессиональных и профессиональных компетенций для овладения трудовыми функциями выпускниками педиатрического факультета уровня высшего образования "специалитет".

Для преподавания дисциплины в 2015 г. разработана рабочая программа, соответствующая современным требованиям учебного процесса, которая была обеспечена дидактическим материалом, учебными видеофильмами. Преподавание дисциплины включает аудиторную (лекции и практические занятия) и внеаудиторную (самостоятельную) работу, которая составляет треть от общей трудоемкости дисциплины. По итогам первых 3 лет преподавания дисциплины в рабочую программу внесены дополнения и изменения.

С целью исследования потребности студентов 6-го курса педиатрического факультета в изучении вопросов вакцинопрофилактики, объективной оценки уровня их исходных знаний в этой области, а также для улучшения качества преподавания проводилось анкетирование в первый день изучения дисциплины и после окончания цикла.

Основным инструментом для проведения данного исследования были специально разработанные анкеты с использованием вопросов открытого, закрытого, полузакрытого типа и применением шкалирования, Googleопросники.

Обработка результатов проводилась при помощи программы, написанной в среде управления банками данных Microsoft Access (в пакете Microsoft Office) для операционной среды Windows XР и выше.

Представляет интерес блок вопросов, позволяющих оценить знания респондентов в области вакцинопрофилактики до начала изучения дисциплины.

Почти половина (42,3\%) студентов пришли на цикл только потому, что дисциплина поставлена в учебный план. И эта цифра свидетельствует о том, что студенты, не имеющие опыта работы в практическом здравоохранении, не могут объективно оценить необходимость знаний в определенных областях.

Приятно отметить, что 96\% студентов 6-го курса педиатрического факультета имеют положительное отношение к вакцинации, но лишь 90\% оценили по 5-балльной шкале важность знаний по вакцинации на “5", нейтральное и настороженное отношение имеют по $2 \%$ респондентов, столько же оценили важность знаний в этой области на «3".

Рассуждая о мотивах отказа родителей от вакцинации своих детей, 98\% студентов считают, что основная причина - информация об опасности прививок, полученная из СМИ, за ней следуют религиозные верования (28\%), сомнения в эффективности и необходимости прививок, излишнее количество прививок (от 30 до 40\% ответов). Анализ ответов студентов-родителей и студентов, не имеющих детей, не выявил различий.

$\mathrm{K}$ сожалению, анализ анкет показал, что около половины опрошенных студентов дали положительный ответ на вопрос "Сталкивались ли вы за время обучения в вузе с антивакцинальными высказываниями/мнением?». При этом практически пятая часть респондентов (17\%) сообщила, что антивакцинальные высказывания слышали от преподавателей на предыдущих курсах обучения, и столько же (17\%) - от однокурсников. Большая часть студентов (58\%) слышали антивакцинальные высказывания от родственников и друзей без медицинского образования.

Отдельно считаем необходимым выделить блок вопросов, который позволил оценить уровень знаний в отношении вакцинопрофилактики на примере вакцинации против пневмококковой инфекции, которая включена в Национальный календарь профилактических прививок (НКПП) в 2014 г. приказом Минздрава РФ.

Практически 100\% студентов знали о вакцинации против пневмококковой инфекции, но лишь половина перечислили все возможные вакцинопредотвратимые заболевания, этиологическим фактором которых может являться пневмококк. Только 86\% студентов на момент начала изучения дисциплины знали, что вакцина против пневмококковой инфекции включена в НКПП как обязательная. Более трети опрошенных не знали различий между вакцинами против пневмококковой инфекции, около половины не смогли обозначить группы лиц, подлежащих вакцинации против этой инфекции.

Кроме того, только 26,22\% студентов считают, что детей с хроническими заболеваниями можно вакцинировать.

После окончания курса было проведено повторное анкетирование студентов. На рисунке представлены варианты ответов, полученные на вопрос "Как изменилось ваше отношение к вакцинопрофилактике после изучения дисциплины?». Ниже приведены некоторые цитаты респондентов*, отражающие группы ответов:

- «Всегда была за прививки и сейчас еще больше убедилась в их необходимости. Теперь с еще большим рвением буду рекомендовать вакцинацию как способ профилактики инфекционных заболеваний»;

- «Всегда был ЗА вакцинацию, кафедра помогла разобраться в вопросах, которые не понимал";

- "Я пока не определилась, но считаю необходимым предупреждать об осложнениях и очень ответственно подходить к исследованию состояния, наследственности ребенка перед вакцинацией".

Результаты анкетирования после цикла показали, что студенты довольны полученными знаниями, однако только $47 \%$ считают, что эти знания пригодятся в профессиональной деятельности. Возможно, такой показатель обусловлен тем, что из опрошенных студентов 6-го курса педиатрического факультета только около трети планируют работать педиатрами в первичном звене, еще около трети опрошенных планируют обучение узкой специальности в педиатрии, а около трети не планируют оставаться в медицине и педиатрии. При этом 100\% опрошенных считают целесообразным преподавание данной дисциплины для выпускников педиатрического факультета в виде дисциплины вариативной части, из них 93\% видят изучение в качестве обязательной дисциплины, $2 \%$ предлагают сделать дисциплиной по выбору, 1\% воздержались.

* Пунктуация и орфография сохранены. 
Рисунок. Варианты ответов, полученные на вопрос «Как изменилось ваше отношение к вакцинопрофилактике после изучения дисциплины?"

Fig. Answer options for the question “How has your attitude towards preventive vaccination changed after studying the discipline?"

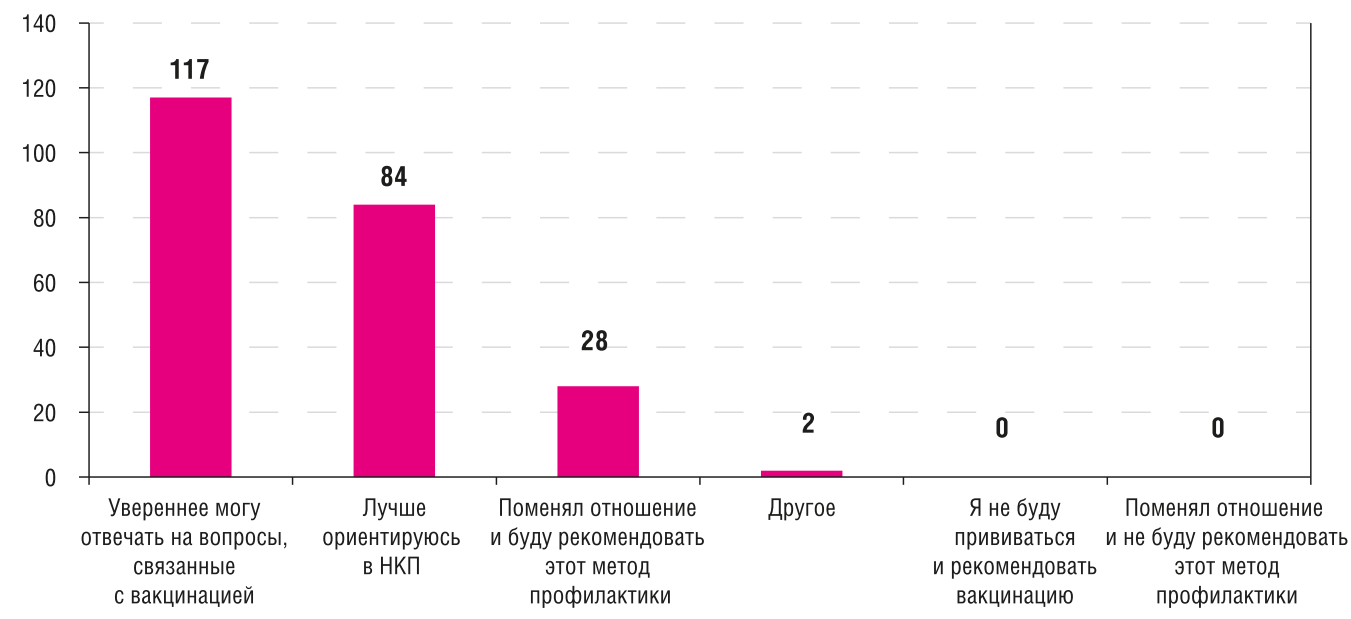

Анализируя все вышесказанное, авторы считают целесообразным ввести в учебный план подготовки специалистов по профилю "педиатрия" уровня высшего образования "специалитет" преподавание дисциплины "Вакцинопрофилактика здоровых детей и детей с хроническими заболеваниями" в виде обязательной дисциплины вариативной части кафедрами педиатрического профиля во всех медицинских вузах страны.

Для апробации необходимо создать пилотный проект, кафедра факультетской педиатрии педиатрического факультета РНИМУ им. Н.И. Пирогова приглашает кафедры педиатрического профиля к участию и готова предоставить методическое обеспечение преподавания дисциплины.

\section{ИСТОЧНИК ФИНАНСИРОВАНИЯ}

Не указан.

\section{FINANCING SOURCE}

Not specified.

\section{КОНФЛИКТ ИНТЕРЕСОВ}

Автор статьи подтвердил отсутствие конфликта интересов, о котором необходимо сообщить.

\section{CONFLICT OF INTERESTS}

Not declared.

\section{ORCID}

Л.С. Намазова-Баранова

https://orcid.org/0000-0002-2209-7531

T.E. Привалова

https://orcid.org/0000-0003-4680-2925

В.А. Булгакова

https://orcid.org/0000-0003-4861-0919

ю.И. Ермакова

https://orcid.org/0000-0002-2944-4858

М.В. Федосеенко

https://orcid.org/0000-0003-0797-5612

Д.С. Русинова

https://orcid.org/0000-0002-1215-1872

T.A. Калюжная

https://orcid.org/0000-0003-1453-4671

Е.А. Вишнева

https://orcid.org/0000-0001-7398-0562

Ф.Ч. Шахтахтинская

https://orcid.org/0000-0002-3270-4374

М.В. Фоминых

https://orcid.org/0000-0002-1184-5290

\section{СПИСОК ЛИТЕРАТУРЫ / REFERENCES}

1. Воз: десять угроз общественному здравоохранению в 2019 году. [VOZ: desyat' ugroz obshchestvennomu zdravookhraneniyu v 2019 godu. (In Russ).] Доступно по: https://news.un.org/ru/ story/2019/01/1348082. Ссылка активна на 05 февраля 2021. 2. Калюжная Т.А., Федосеенко М.В., Намазова-Баранова Л.С. и др. Преодоление "антипрививочного скепсиса": поиски решения выхода из сложившейся ситуации // Педиатрическая фармакология. 2018. - T. 15. - № 2. - C. 141-148. [Kaliuzhnaia TA, Fedoseenko MV, Namazova-Baranova LS, et al. Overcoming 'Anti-Vaccination Scepticism': Seeking a Solution to the Situation. Pediatricheskaya farmakologiya - Pediatric pharmacology. 2018;15(2): 141-148. (In Russ).] https://doi.org/10.15690/pf.v15i2.1871

3. Приказ Минздрава России от 21 марта 2014 г. N 125н "Об утверждении национального календаря профилактических прививок и календаря профилактических прививок по эпидемическим показаниям" (в ред. Приказов Минздрава России от 16.06.2016 N 370н, от 13.04.2017 N 175н. от 19.02.2019 N 69н, от 24.04.2019 №243H). [Prikaz Minzdrava Rossii ot 21 marta 2014 g. N 125n “Ob utverzhdenii natsional'nogo kalendarya profilakticheskikh privivok i kalendarya profilakticheskikh privivok po epidemicheskim pokazaniyam" (v red. Prikazov Minzdrava Rossii ot 16.06.2016 N 370n, ot 13.04.2017 N 175n. ot 19.02.2019 N 69n, от 24.04.2019 №243n). (In Russ).]

Статья поступила: 28.01.2020, принята к печати: 19.02.2021 The article was submitted: 28.01 .2020 , accepted for publication: 19.02 .2021 